\title{
Hydrology Experiment Design: An Open-Ended Lab to Foster Student En- gagement and Critical Thinking
}

\section{Dr. Cara J Poor P.E., University of Portland}

Dr. Poor teaches many of the integral undergraduate civil engineering courses at University of Portland, including hydraulics, fluids, and environmental engineering. Dr. Poor is a licensed professional engineer with ongoing research in green infrastructure design, water quality, watershed management, and engineering education. She is currently developing new curricula for hydraulics, fluids, and environmental engineering labs, and conducting research on methods to improve conceptual understanding and critical thinking.

\section{Evan S Miller, GeoEngineers, Inc.}

Evan graduated from Washington State University with a masters in civil engineering with emphasis on water resources. Post graduation, Evan primarily works in the field of river and habitat restoration. Projects of this nature involve many areas of water resource engineering including hydrology, hydraulics, open channel design, one and two dimensional hydraulic modeling, AutoCAD and ArcGIS plan design, and project coordination. 


\section{Hydrology experiment design: an open-ended lab to foster student engagement and critical thinking}

\section{Introduction}

In traditional civil engineering hydraulics classes, students get little if any hands-on experience with hydrology. Hydrology is typically presented using rainfall-runoff or hydrograph plots and explanations of physical phenomena. Labs that do include hydrology apparati often only demonstrate a simple rainfall-runoff relationship with a saturated, uniform media such as sand. Students do not see effects of slope, vegetation, development, impoundments, and other landscape characteristics, or subsurface flow, infiltration to groundwater, and other hydrologic processes. In addition, it is difficult to relate a basin filled with sand to an actual basin with vegetation, slope, development, etc. This often leads to poor understanding of hydrologic processes and lack of interest.

Conceptual understanding, or the ability to explain or predict phenomena ${ }^{1}$, is integral to success as an engineer. Students often develop the ability to plug numbers into equations and get an answer without understanding what the answer means, and they are not able to apply equations to new or different scenarios ${ }^{2,3}$. Practicing engineers must be able to apply multiple fundamental concepts to various design problems, and conceptual understanding is the first step in developing this ability ${ }^{2,4,5}$. Computer technology, including hydrologic models and mapping tools, and engineering technology is rapidly changing, requiring engineers to constantly learn to stay competitive. The ability of an engineer to quickly learn new technology and apply it is grounded in understanding fundamental concepts.

Only a few studies have focused on developing hydraulics labs ${ }^{6,7}$. At Washington State University, an open channel lab was developed to improve conceptual understanding of hydraulic jumps and weirs ${ }^{6}$. Students are guided through the lab, then asked to design a weir to reduce the power of the vortex created by the hydraulic jump downstream of the weir. Students were enthusiastic about the lab, and it fostered further discussion. At University of Queensland, both laboratory and field studies were introduced to increase student interest ${ }^{7}$. Student feedback indicated that lab and field studies helped them think more critically about hydraulics, which is reflected by the decrease in failure rates from $15-30 \%$ to $5-22 \%$. Hands-on work in the lab and field can help students make connections between concepts and improve conceptual understanding, and has strong industry support ${ }^{7}$. Both lab and field studies have focused on open channel hydraulics, but very little is typically done for hydrology. Similar studies developing hydrology labs are needed to improve understanding of fundamental hydrologic concepts.

As development in urban areas and water demands increase due to growing populations, it is becoming increasingly important for engineers to understand and consider hydrologic concepts in the design stage. To create the same interest and excitement observed with open channel labs ${ }^{6}$ and improve conceptual understanding of hydrologic concepts, an open-ended lab activity with a hydrology apparatus was designed for civil engineering students. The lab activity was first evaluated with student volunteers, improved based on feedback from the volunteers, then added to an Engineering Hydraulics Laboratory class. Student understanding was evaluated with a 
conceptual quiz before and after the lab activity, and survey questions were used to evaluate student interest and enthusiasm.

\section{Methodology}

The open-ended lab activity was developed with a TecQuipment hydrology apparatus (Figure 1). The hydrology apparatus consists of a 4-foot wide by 6-foot long box filled with 1 foot of silica sand. Rainfall is simulated using 8 controlled water sprayers approximately 2 feet above the sand surface. The sprayers are on a rectangular grid measuring 1.65 feet by 1.65 feet. Water comes out of the sprayers to simulate rainfall, then infiltrates into the silica sand until saturation occurs. Groundwater flow and runoff are collected at the outlet of the basin model and routed through a small weir where students can measure flow rate. Runoff is routed to a tank, and a pump recirculates the water to the sprayers. Students measure inflow, outflow, and duration and plot to create rainfall-runoff hydrographs.

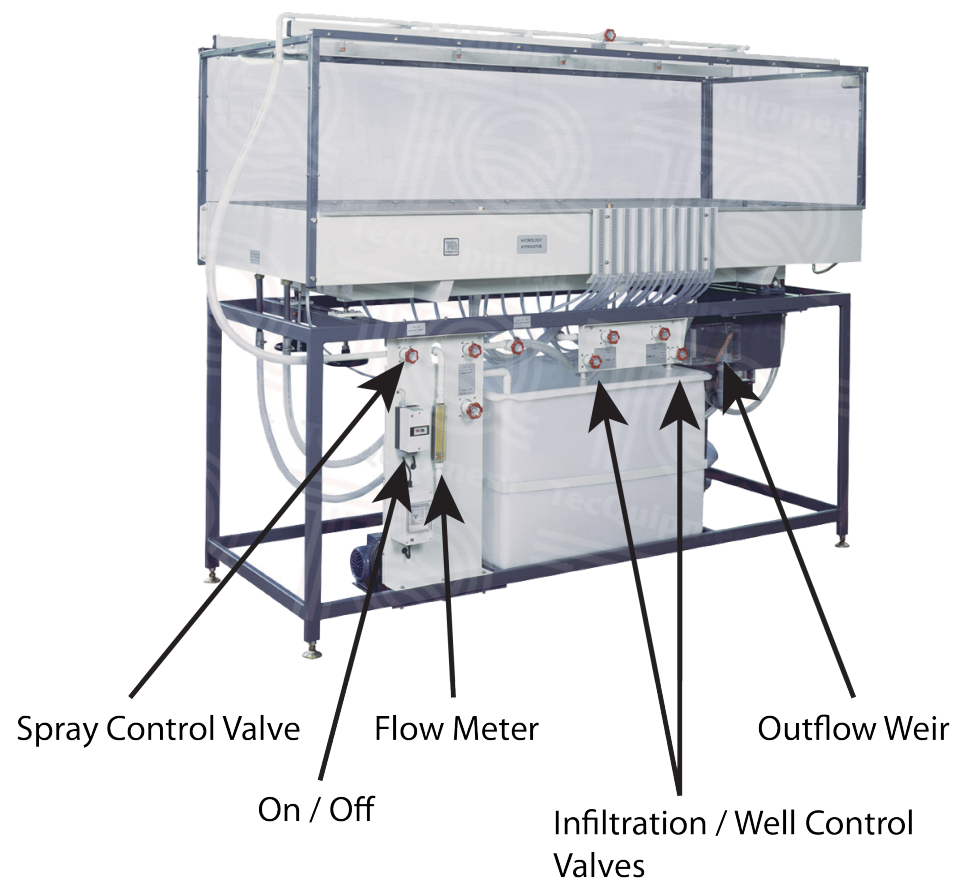

Figure 1. TecQuipment Hydrology Apparatus (source: www.tecquipment.com)

The functionality of this apparatus was improved by providing the ability to insert different materials into the apparatus, which have the effect of changing the resulting runoff hydrograph in different ways. Students can observe the effects of deforestation or land use changes by comparing the hydrograph from the sand basin to the hydrograph from the basin with turf or a foam pad. These materials intercept and slow the movement of water in the basin resulting in a lower peak flow and longer time to concentration. Blocks representing houses and buildings and a rubber mat are also available for students to observe the effects of increasing impervious area as a result of development (higher peak flow, shorter time to concentration). Detention storage (lakes, dams, reservoirs, and infiltration basins) can be simulated by making depressions in the soil or using flexible plastic inserts. In addition, many other hydrologic variables may be 
changed using the hydrology apparatus: basin slope, landforms (hills and valleys), antecedent soil moisture, rainfall rates and rainfall duration. After taking measurements in the lab, the students create hydrographs for each of their scenarios, enabling them to compare different conditions.

Hydrology Lab Design. The lab was developed to be open-ended and provided an opportunity for students to design their own experiment. Students are first shown how the hydrology apparatus worked and what materials were available. They are then asked to review current literature and develop 2 testable questions based on 2-3 relevant journal articles. Testable questions are questions that can be answered by comparing one scenario or modification to a control in a lab experiment. Possible testable questions include:

1. How do impervious surfaces change the runoff hydrograph?

2. How does detention storage impact time of concentration?

3. How does deforestation affect peak flow?

Students are then asked to write a procedure for their experiments. Once the instructor approves their testable questions and procedure, the students conduct their lab experiment and write a lab report. Figure 2 shows an example of a setup to evaluate the effect of detention storage. Four hydrographs (2 for each testable question) are produced, a control hydrograph and a hydrograph with the modification for each question (i.e., Figure 3). Students compare these hydrographs to evaluate the test question. The hydrographs shown in Figure 3 were developed to evaluate the impact of having $100 \%$ impervious surface by fully covering the basin with the rubber mat, and the impact of including a bio-swale by installing a section of turf in the runoff channel. The control for both of these modifications was the same: the basin with no rubber mat or turf (sand only). 


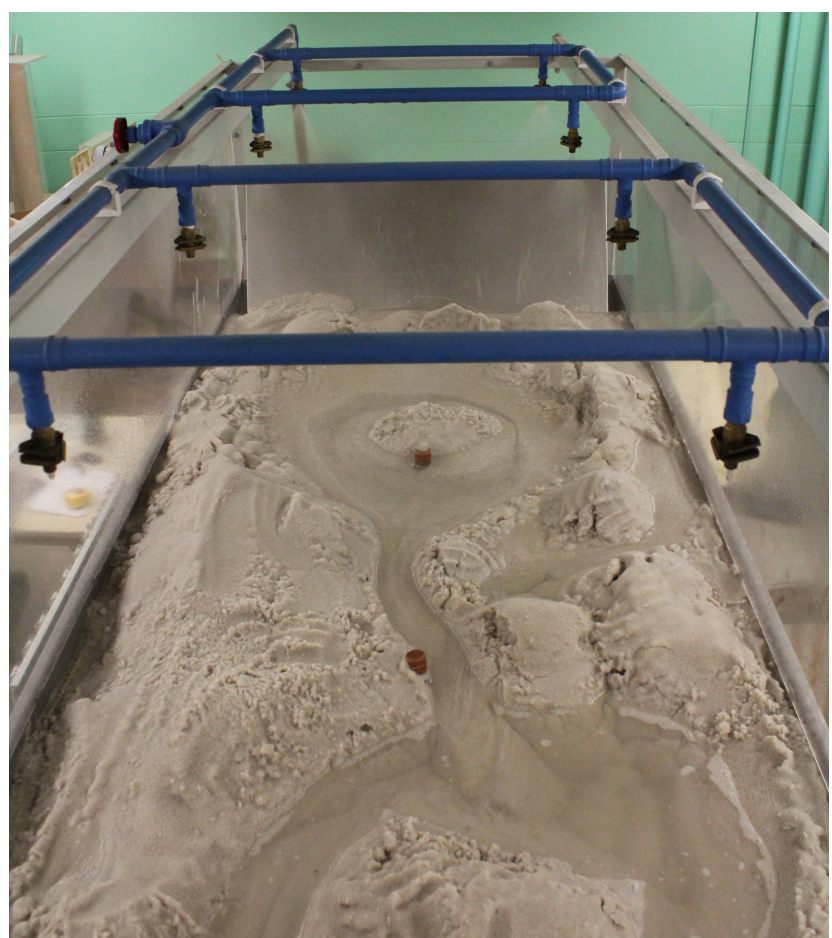

Figure 2. Example setup to evaluate the effect of detention storage.

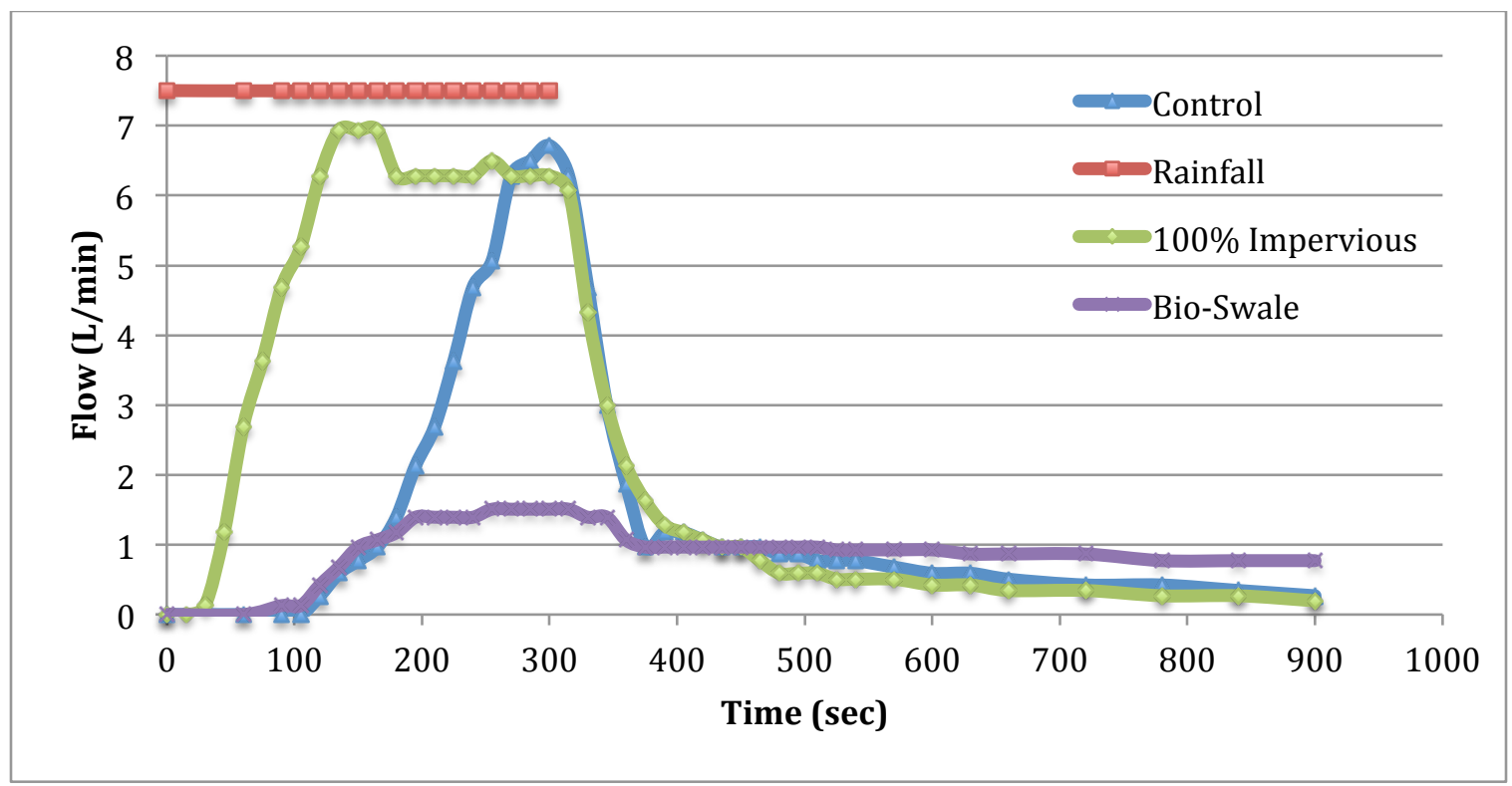

Figure 3. Possible hydrographs developed from testable questions.

Evaluation of Lab Design. This newly designed hydrology lab was first tested with 16 volunteers. Experience level varied from graduate students to undergraduate students who had not taken hydraulics or hydrology. A pre- and post-test was given to the volunteers to evaluate how the lab improved conceptual understanding and enthusiasm for the lab. The pre-test consisted of eight hydrology conceptual questions, and the post-test included the same hydrology 
conceptual questions in addition to three questions that allowed students to rate the effectiveness of the lab. Pre- and post-test questions are included in the appendix. After taking the pre-test, the volunteers completed the assignment. The assignment was modified slightly by providing journal articles for students to look through so volunteers could complete the assignment and experiment in one session. The regular assignment requires students to do a literature search and develop a procedure prior to the lab. We wanted the volunteers to be able to complete the assignment in one session, and not have to do extra work outside of the time they were in the lab. Students developed their two testable questions and procedure, and ran the experiments. They then plotted and evaluated their results. After a discussion of results among peers (similar to what would occur in a lab group), the volunteers took the post-test. Results from the pre- and post-test were then compared to determine the effectiveness of the lab.

The following semester, the new lab was assigned to 32 students in an Engineering Hydraulics Laboratory class. All students were senior undergraduates in Civil Engineering. Hydraulics is a pre-requisite to the lab class, so all students understood basic hydrologic concepts. Based on feedback from the volunteers, more explanation and guidance was included. Ideas were also discussed in class when writing the procedure to guide students in their literature search. The pre-test evaluated conceptual understanding of hydrology with lecture only. The post-test evaluated how conceptual understanding improved with the addition of the lab, and gave students an opportunity to evaluate the lab.

For both the volunteers and the class, the individual questions were graded on a 1-5 metric based on how complete and correct the answer. A value of 1 was assigned for no answer, or a completely wrong answer. A value of 3 was assigned for an answer that was $50 \%$ correct or only answered part of the question, and a value of 5 was assigned for a $100 \%$ correct answer. Values of 2 and 4 were assigned is the answers were $25 \%$ and $75 \%$ correct, respectively. A single person did all of the evaluations.

A standard gains formula (Equation 1) was used to calculate the percent increase or decrease between the pre- and post-test scores, and helps normalize the scores to minimize bias from the pre-test scores (i.e., how much they already knew). This formula has been used to evaluate the effectiveness of other lab designs, including open channel desktop learning modules in a Water Resources class ${ }^{8}$.

$$
\text { Gains } G=\frac{\Delta \text { score }}{\text { Points Possible to Gain Back }}=\frac{\text { Post Test Score }- \text { Pre Test Score }}{\text { Total Points Possible }- \text { Pre Test Score }}
$$

The three additional questions on the post-test provided an opportunity for students to evaluate how well the lab helped improve their understanding of hydrology concepts. Students answered these questions on a Likert scale:

5 Strongly Agree

4 Somewhat Agree

3 Neutral

2 Somewhat Disagree

1 Strongly Disagree 
Questions are asked as declarative statements, followed by varying degrees of agreement with or against the statement ${ }^{9}$. The Likert scale is very useful in this type of application and has proven successful in many diverse applications ${ }^{9}$.

\section{Results and Discussion}

Volunteer Group. A total of 16 volunteer students participated in the hydrology lab, 5 graduate and 11 undergraduate students. The majority of participants showed improvement between the pre- and post-tests (Figure 4).

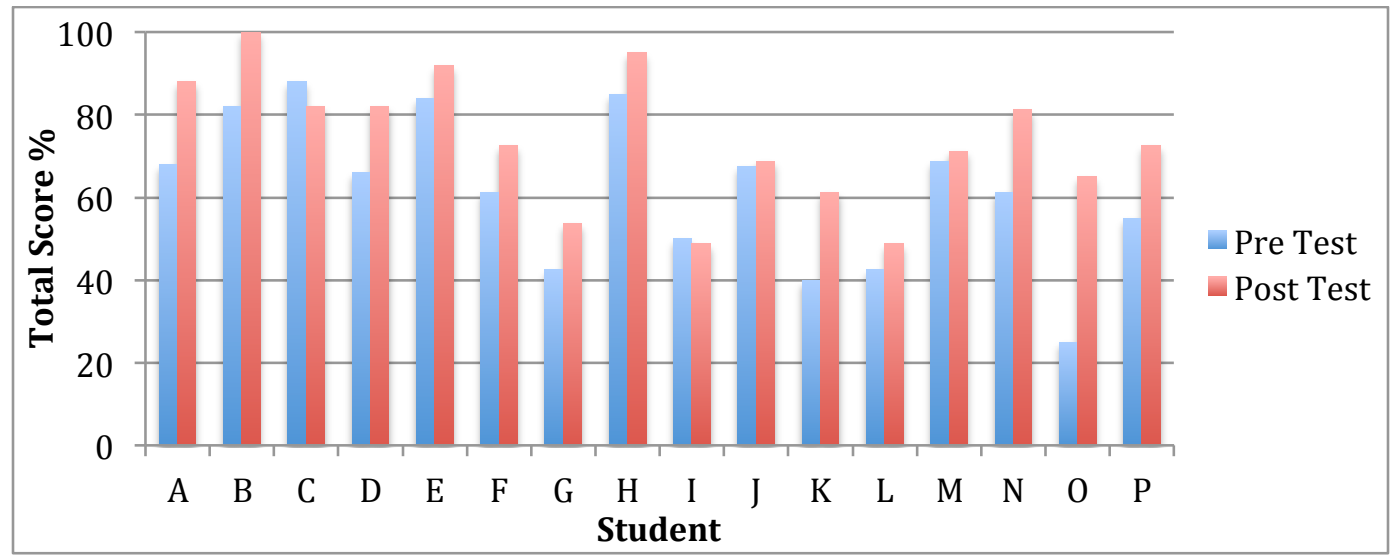

Figure 4. Pre- and Post-Test Scores for each volunteer.

The volunteers had an average gain of 0.31 out of 1.0 possible. Graduate students gained an average of 0.37 and undergraduates gained 0.26 . The graduate students had a higher increase in gains, but the average increase in score was lower. Graduate student scores increased an average of 2.8 points whereas undergraduate scores increased an average of 5.1 points. Because graduate students had higher pre-test scores, the possible increase in scores was less. This produced the effect of creating higher gains with lower amount of increased points. For example, an increase from $9 / 10$ points to $10 / 10$ points is an increase of 1 point and $100 \%$ of the possible points were gained. This results in a gain of 1 . Conversely, increasing from $4 / 10$ points to $8 / 10$ points is an increase of 4 points and $66 \%$ of the possible points were gained. This results in a gain of 0.66 . Thus, graduate student scores increased fewer points but had higher gains.

Two of the student volunteers did not have any previous experience with hydrology and achieved the highest gains of 0.47 and 0.62 . This is likely because they were less familiar with hydrology concepts and scored low on the pre-test, but understood much more after completing the lab. Other students who already knew these concepts coming into the lab had less room for improvement. For these students, the hydrology lab was a very effective tool for understanding hydrology concepts.

Results of the student evaluation are shown in Table 1. Most students answered these questions with a 4 (Somewhat Agree) or 5 (Strongly Agree). In general, the volunteers believed the lab activity helped them visualize and see links between hydrologic concepts. They also thought their understanding of hydrologic concepts improved, although some students answered with a 3 
(Neutral). This may be due to the background of those students; they had taken a lecture class that covered hydrology concepts so may not have believed there was as much value in the hydrology lab as the other volunteers.

Table 1. Volunteer Evaluation of Hydrology Lab.

\section{Questions}

Average

Answer

As a result of this lab, my understanding of hydrologic concepts has improved.

This lab helped me visualize hydrology concepts.

Engineering Hydraulics Laboratory Class. The 32 students in the Engineering Hydraulics Laboratory also showed improvement as a result of the hydrology lab (Figure 5). All students except six improved their scores between the pre- and post-tests. Four of these students missed one more point on the post-test compared to the pre-test, and two of the students missed 4 or more additional points on the post-test.

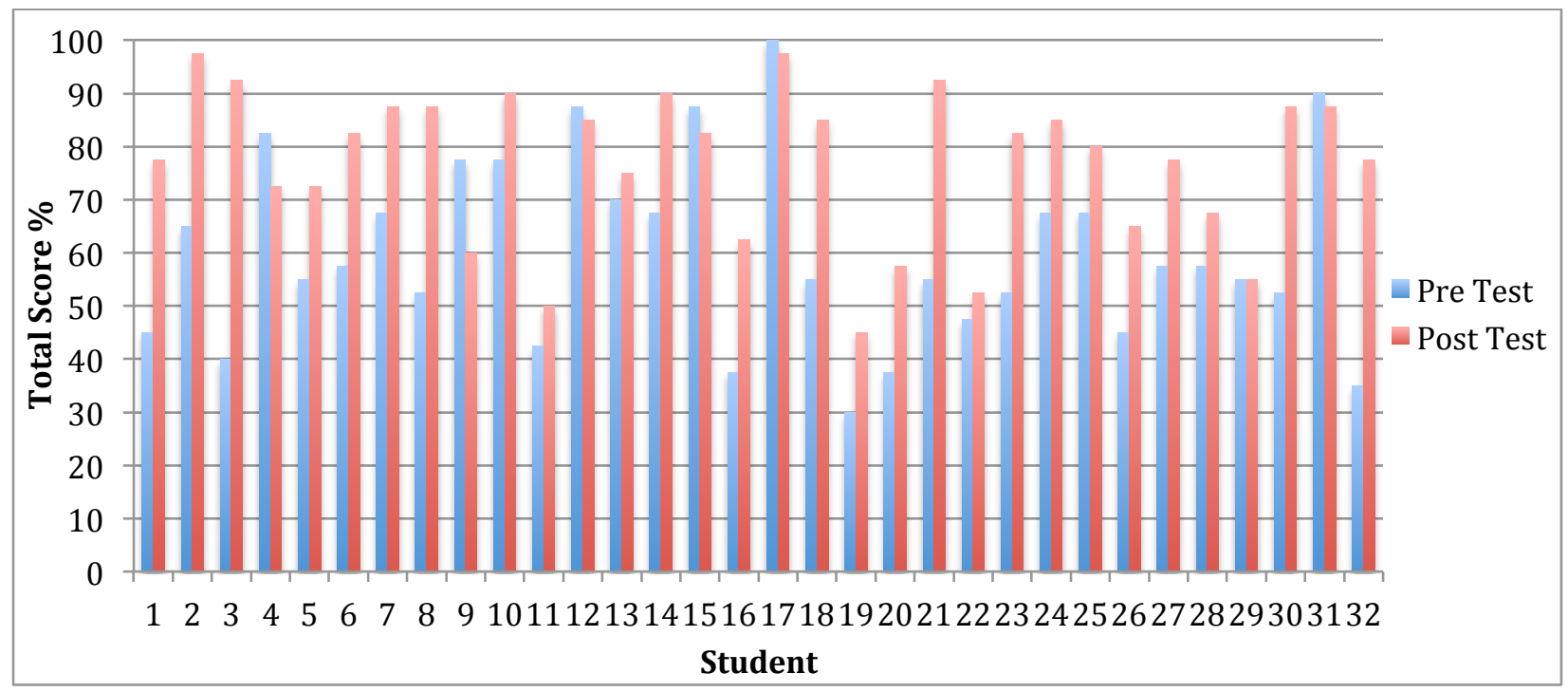

Figure 5. Pre- and Post-Test Scores for each student in the Engineering Hydraulics Lab.

Average gain was 0.30 , which is very similar to volunteer results. If the negative gains are removed, average gain increases to 0.47 . Several students had significant gains higher than 0.5. The highest gain was 0.93. This student had taken Hydraulics a year prior (compared to the previous semester when the other students took Hydraulics), and may have forgotten some of the hydrology concepts. The lab helped this student remember and reinforce hydrology concepts learned previously. Many students showed large gains as a result of the lab, indicating that it was a useful lab for improving conceptual understanding of hydrology. There was also one student who scored $100 \%$ on the pre-test, so had no room for gains. The lab did not improve this 
student's ability to answer conceptual questions on a quiz, but there still may have been some benefit of seeing hydrologic processes.

Like the volunteers, the students in the class thought that the lab improved their understanding of hydrology as well as their confidence in answering hydrology conceptual questions (Table 2). Most students answered these questions with a 4 (Somewhat Agree) or 5 (Strongly Agree). In general, the students enjoyed the lab activity and believed it helped them visualize and see links with hydrologic concepts. They also thought their understanding of hydrologic concepts improved, although some students answered with a 3 (Neutral). This may be due to the Hydraulics lecture class they had taken the previous semester; they had already been exposed to hydrology concepts so may not see the value in the hydrology lab. For future classes, this lab class may be offered in conjunction with the Hydraulics class, or the importance of visualization may be emphasized more.

Table 2. Student Evaluation of Hydrology Lab.

\section{Questions}

As a result of this lab, my understanding of hydrologic concepts has improved.

This lab helped me visualize hydrology concepts.

This lab helped me see the link between hydrographs and physical processes.

\section{Average}

Answer

4.1

\section{Conclusions and Future Research}

Using an existing piece of equipment and relatively inexpensive materials, an open-ended lab was created that improved student understanding of hydrology and created enthusiasm for this area of engineering. Students had to think critically to develop testable questions and a procedure. Due to the open nature of the lab, this process also fostered student ownership of their learning. Overall, this open-ended lab activity was beneficial to student learning and improved student understanding. Results indicate there were gains in student understanding, and students recognized the value of the assignment. Because this hydrology apparatus is so large, next steps include building smaller, desktop models that can be used in the classroom setting. This will enable this open-ended lab activity to be disseminated to a larger population of students.

To increase students' ability to design their own lab experiment, other materials could be added to test different effects, such as climate change. Discussions relating to climate change could be added to the hydraulics lab class curriculum and integrated into the open-ended lab activity. One simple example of testing the effects of climate change would be to model the decreased storage and early release of water from snow pack located in mountainous regions. A pile of snow could be placed on the hydrology apparatus and allowed to slowly melt. To evaluate the effects of climate change, a hair dryer or other means for increasing the rate of snowmelt could be used. Runoff flowpaths and rates could then be observed. Students could also evaluate the effects of soil type, compaction, and other factors if different soil types (silt and clay), a small compactor 
or tamper, and other materials were available. This open-ended lab activity provides opportunity for students to explore hydrology concepts without being limited to one specific lab procedure.

\section{References}

1. Vosniadu, S. (1994). Capturing and Modeling the Process of Conceptual Change. Learning and Instruction 4(1): 45-69.

2. Streveler, R.A., Litzinger, T.A., Miller, R.L., and Steif, P.S. (2008). Learning Conceptual Knowledge in the Engineering Sciences: Overview and Future Research. Journal of Engineering Education 97(3): 279-294.

3. Richards, D.E. and Collura, M.A. (2015). Understanding a New Paradigm for Engineering Science Education Using Knowledge about Student Learning. Proceedings of the 2015 Annual Conference of the American Society of Engineering Education, Paper ID\# 12246, Seattle, WA.

4. National Resource Council (2005). How Students Learn: Science in the Classroom. Committee on how People Learn. Division of Behavioral and Social Sciences and Education, M.S. Donovan and J.D. Bransford, eds. The National Academies Press, Washington, D.C.

5. Redish, E.F. and Smith, K.A. (2008). Looking beyond Content: Skill Development for Engineers. Journal of Engineering Education 97(3): 295-307.

6. Hotchkiss, R.H. (2001). Flow over a "Killer" Weir Design Project. Journal of Hydraulic Engineering 127(12): 1022-1027.

7. Chanson, H. (2004). Enhancing Students' Motivation in the Undergraduate Teaching of Hydraulic Engineering: Role of Field Works. Journal of Professional Issues in Engineering Education and Practice 130(4): 259-268.

8. Brown, S., Easley, A., Montfort, D., Adam, J., Van Wie, B., Olusola, A., Poor, C., Tobin, C., Flatt, A. (2014). Effectiveness of an Interactive Learning Environment Utilizing a Physical Model. Journal of Professional Issues in Engineering Education and Practice 140(3).

9. DeVellis, R.F. (2003). Scale Development, Theory and Applications, Second Edition. Applied Social Research Methods Series, Volume 26. Sage Publications, Thousand Oaks, CA. 
Appendix: Pre- and Post-Test Questions

\section{Hydrology Lab Pre and Post Test}

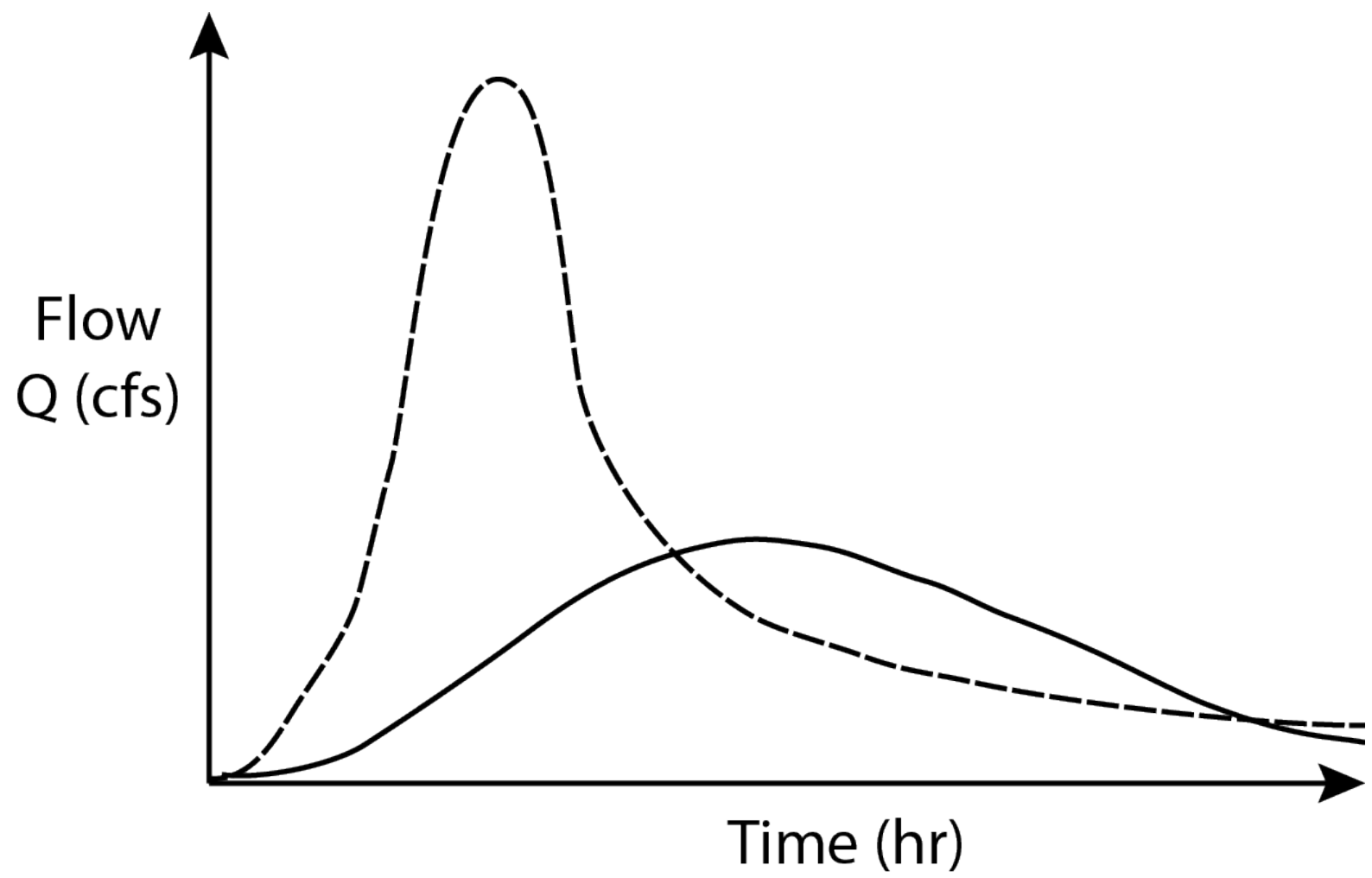

Question 1:

Characterize these two hydrographs.

How well do you feel you answered this question? $1=$ Poor, $10=$ Excellent

$1-2-3-4-5-6-7-8-9-10$ 


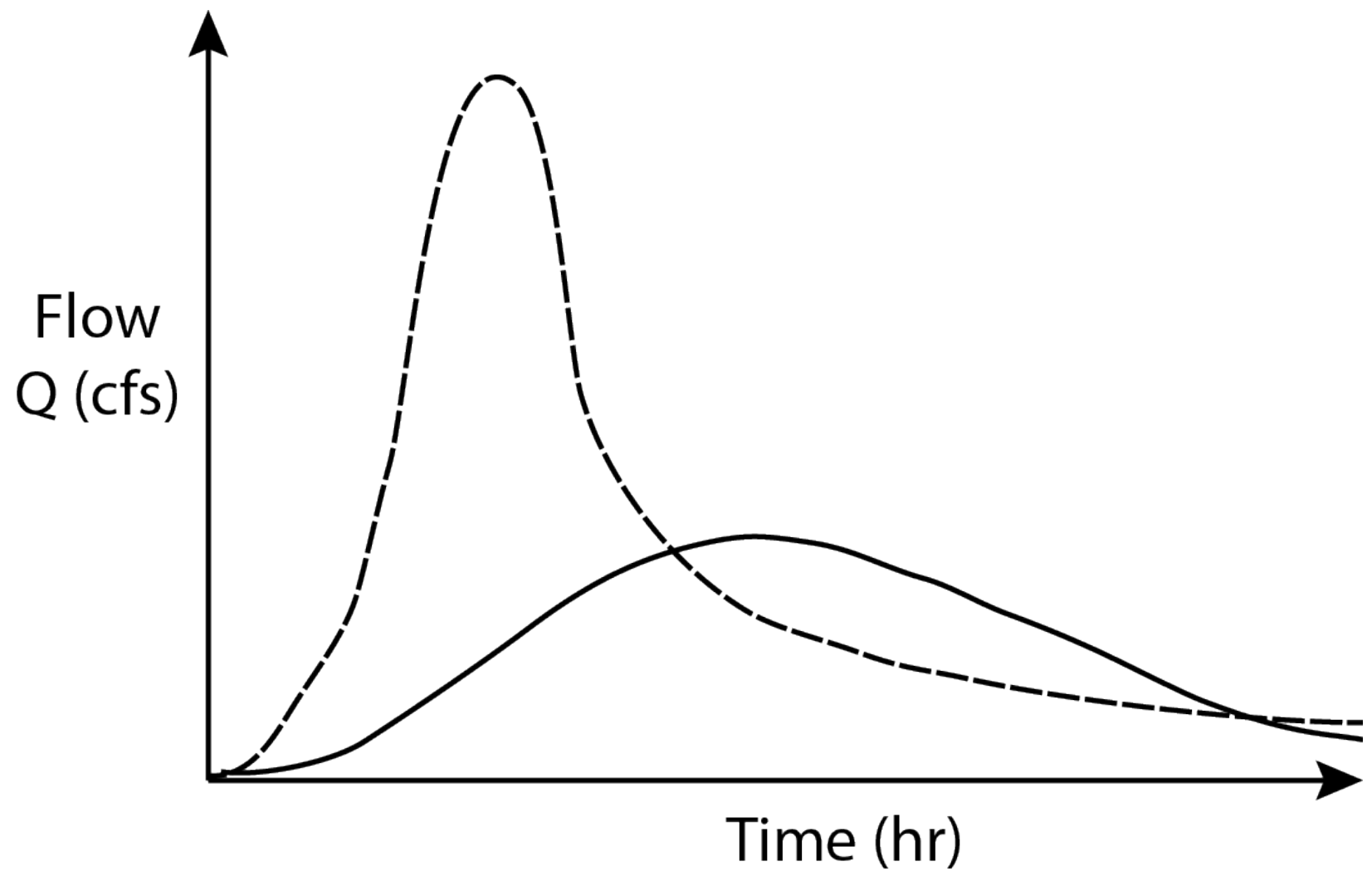

Question 2:

What factors cause the difference between the two hydrographs?

How well do you feel you answered this question? $1=$ Poor, $10=$ Excellent $1-2-3-4-5-6-7-8-9-10$ 


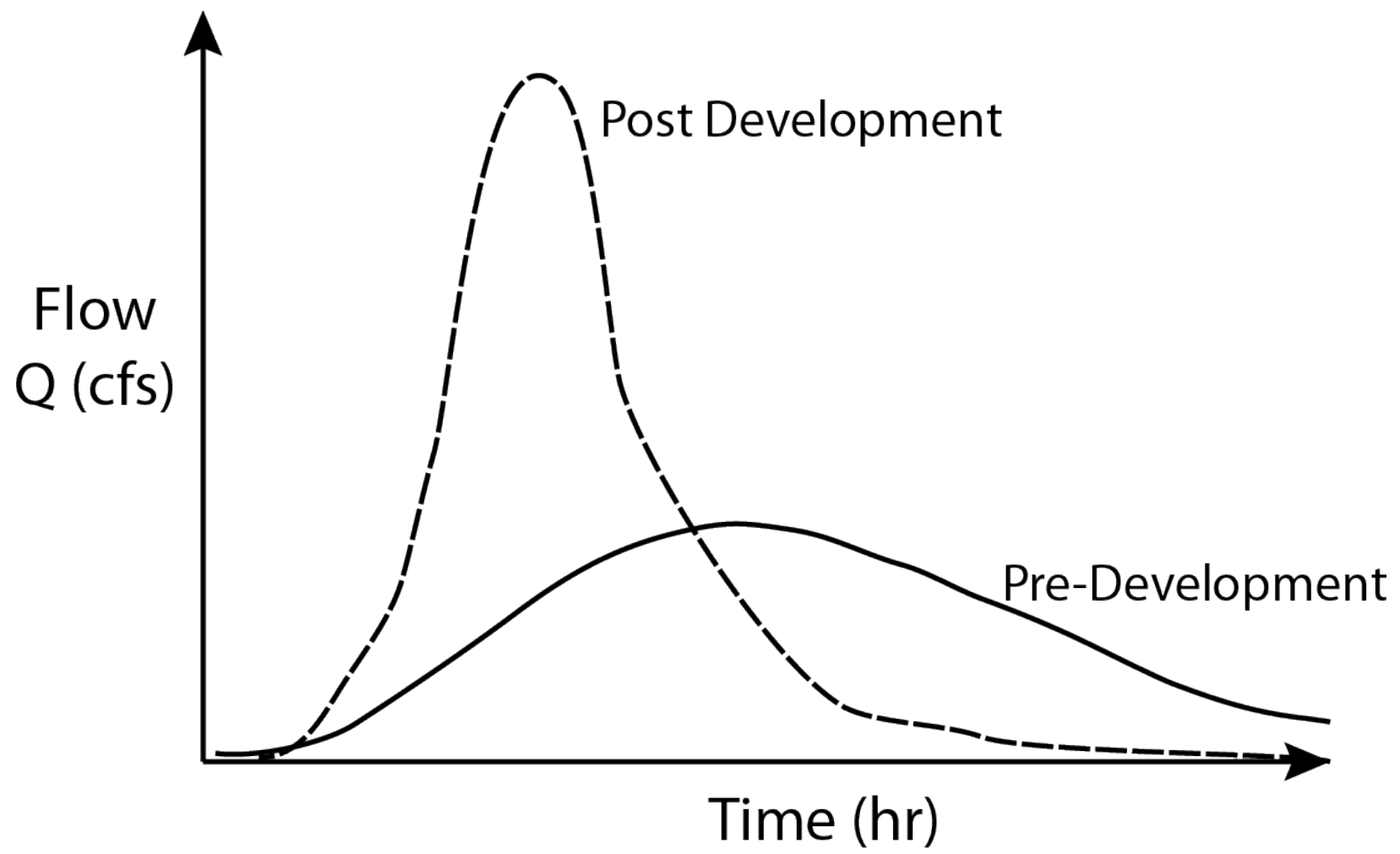

Question 3:

Explain why there is a difference between the pre and post development hydrographs.

What are some engineering solutions that may mitigate the post development hydrograph resulting in a pre development behavior?

How well do you feel you answered this question? $1=$ Poor, $10=$ Excellent

$$
1-2-3-4-5-6-7-8-9-10
$$




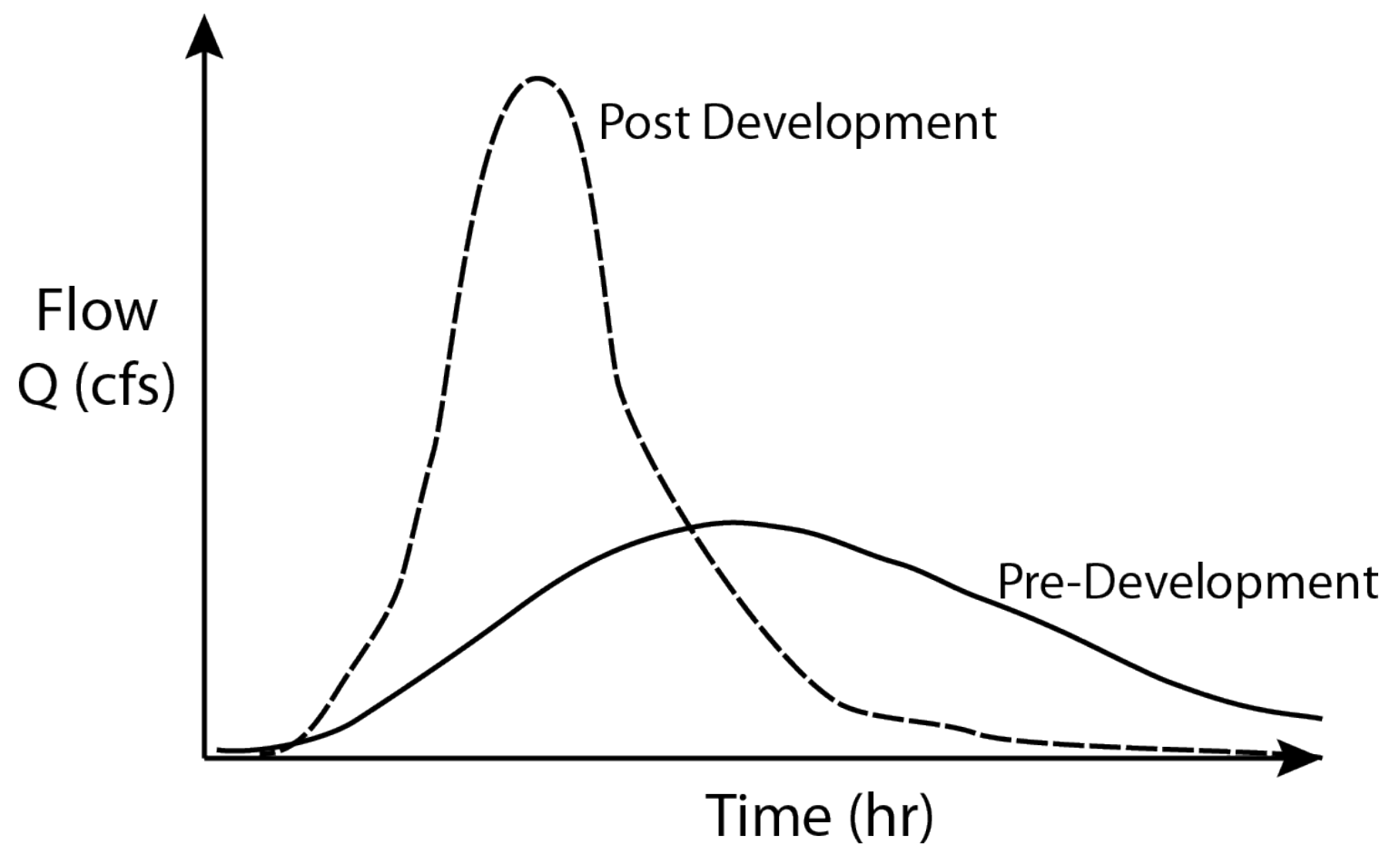

\section{Question 4:}

List some land use changes that could be implemented to mitigate this post development hydrograph

How well do you feel you answered this question? $1=$ Poor, $10=$ Excellent

$$
1-2-3-4-5-6-7-8-9-10
$$

\section{Question 5:}

Identify the possible flow paths water can travel in a watershed.

\section{Question 6:}

Describe the different ways that overland flow can occur. 


\section{Question 7:}

Explain how the outflow source (flow paths) changes over time. Include a sketch of the hydrograph showing different sources over time.

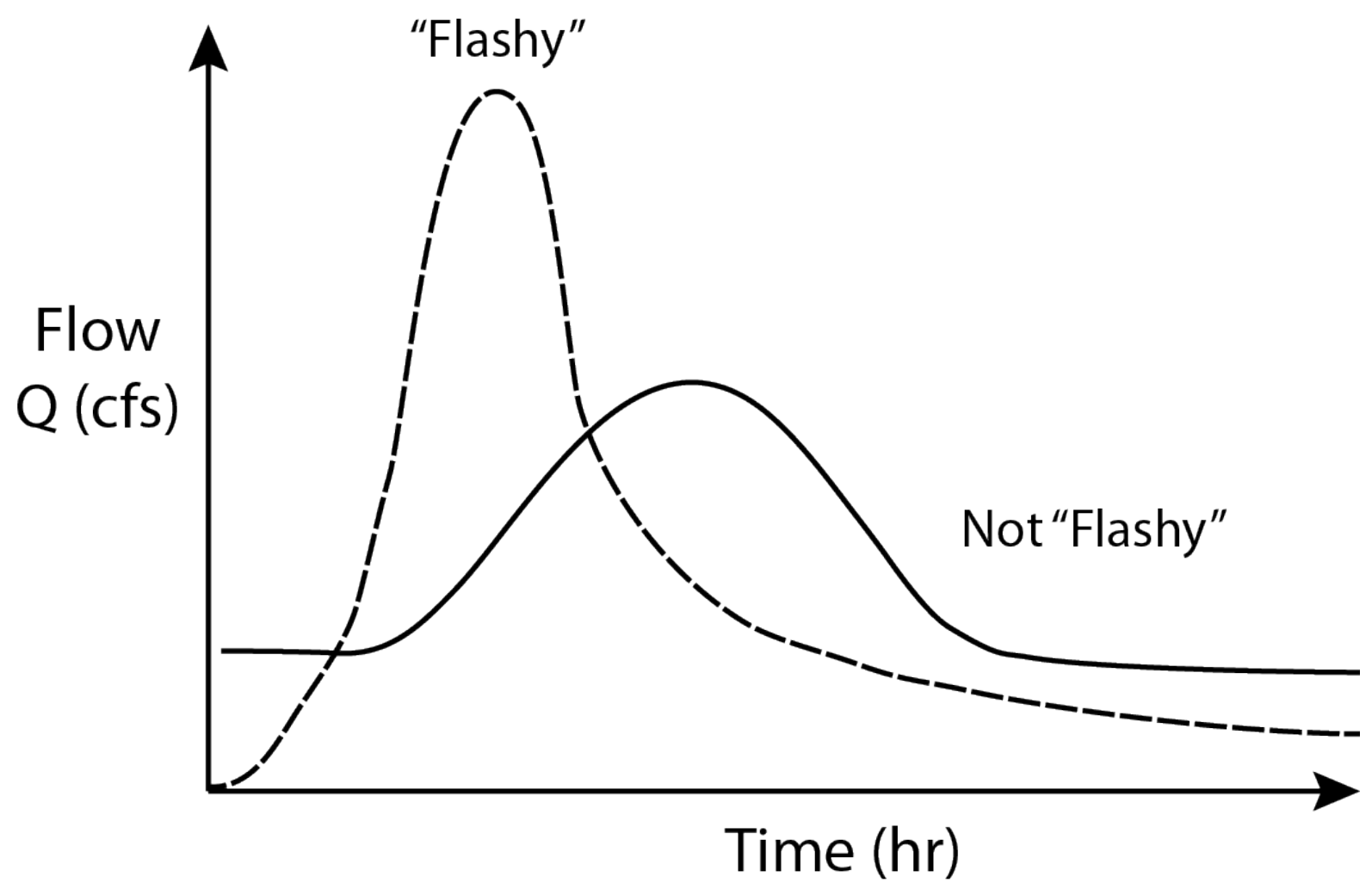

\section{Question 8:}

The above figure shows one stream that is considered flashy and one that is not considered flashy. What are the possible sources of stream flow for the two streams?

How well do you feel you answered this question? $1=$ Poor, $10=$ Excellent $1-2-3-4-5-6-7-8-9-10$ 


\section{Question 9 (Post-Test Only)}

As a result of this lab, my understanding of hydrologic concepts has improved.

5 (Strongly Agree)

4 (Somewhat Agree)

3 (Neutral)

2 (Somewhat Disagree)

1 (Strongly Disagree)

\section{Question 10 (Post-Test Only)}

This lab helped me visualize hydrology concepts.

5 (Strongly Agree)

4 (Somewhat Agree)

3 (Neutral)

2 (Somewhat Disagree)

1 (Strongly Disagree)

\section{Question 11 (Post-Test Only)}

This lab helped me see the link between hydrographs and physical processes.

5 (Strongly Agree)

4 (Somewhat Agree)

3 (Neutral)

2 (Somewhat Disagree)

1 (Strongly Disagree) 